\title{
Prototipe Game Musik Bambu Menggunakan Engine Unity 3D
}

\author{
Michello Pratama Tjahyadi( ${ }^{(1)}$, Alicia Sinsuw ${ }^{(2)}$, Virginia Tulenan ${ }^{(3)}$, Steven Sentinuwo $^{(4)}$ \\ ${ }^{1,2,3}$ Program Studi Teknik Informatika, Fakultas Teknik, Universitas Sam Ratulangi \\ Jl. Kampus UNSRAT Bahu, Manado, 95115 \\ Telp : (0431) 852959, Fax : (0431) 823705 \\ E-mail : mico.suwandi@gmail.com ${ }^{(1)}$, aliciasinsuw@yahoo.com ${ }^{(2)}$, virginia.tulenan@gmail.com ${ }^{(3)}$
}

\begin{abstract}
Abstrak
Tujuan pembuatan prototipe game musik bambu menggunakan engine Unity 3D adalah membuat sebuah rancangan awal game yang bertemakan kebudayaan daerah dan game ini dimainkan dengan mode firstperson yaitu pandangan pemain terhadap player adalah pandangan orang pertama. Juga menggunakan setiap fitur-fitur yang ada didalam game engine Unity untuk membuat game. Dengan memainkan game ini, pemain akan mendapatkan informasi mengenai alat musik bambu mulai dari bentuk alat musik bambu dan suara yang dihasilkan masing-masing alat musik bambu. Metodologi yang digunakan dalam perancangan prototipe game musik bambu yaitu metode Rapid Game Prototyping yang merupakan metode gabungan antara proses rekayasa perangkat lunak pemrograman ekstrem dengan metode game desain. Perancangan pembuatan game ini diakukan dengan membuat model yang menjelaskan setiap kegiatan secara detail dengan menggunakan Unified Modelling Language (UML). Simpulannya adalah prototipe game musik bambu adalah sebuah game yang mengandung nilai-nilai pendidikan mengenai kebudayaan daerah khususnya alat musik bambu Minahasa.
\end{abstract}

Kata Kunci: Perancangan game, Musik bambu Minahasa, engine Unity 3D

\section{PENDAHULUAN}

Perkembangan komputer selama beberapa dekade ini terbilang sangat pesat dan sangat mempengaruhi gaya hidup setiap orang. Seiring pesatnya perkembangan komputer, game komputer juga berkembang dengan pesat dan menjadi salah satu hiburan utama untuk mengisi waktu luang baik dilakukan bersama atau pribadi.

Ada banyak genre game yang sudah dikembangkan sejauh ini seperti RPG(Role-Playing-Game), Adventure, Arcade, Simulation, RTS(Real-Time-Strategy), Edutainment dan lain-lain. Dari tiap genre game tersebut terdapat juga berbagai tema yang menjadi dasar dari game, salah satunya adalah collectible. Dalam game collectible ini tentunya ada objek yang digunakan sebagai elemen utama untuk dikumpulkan atau di collect

Musik bambu merupakan kebudayaan daerah yang sudah mulai hilang ditelan zaman, dengan perkembangan teknologi seperti sekarang ini, pengetahuan dan keinginan untuk mendengar alat musik bambu sangat kurang. Karena itu penulis membuat prototipe game dengan genre edukasi dengan menggunakan Unity $3 D$ dengan tujuan untuk melestarikan kebudayaan daerah yaitu alat musik bambu dan menjadikan game ini sebagai sarana pengenalan musik bambu.

\section{LANDASAN TEORI}

\subsection{Pengertian Game}

Game dapat diartikan[1] sebagai kegiatan penyelesaian masalah, didekati dengan sikap yang menyenangkan, game juga sesuatu yang membuat pemain menemukan kesenangan dalam memainkannya. Game yang bagus adalah game yang dapat membuat pengguna berpartisipasi secara aktif dan mempunyai jumlah tantangan yang tepat, tidak terlalu sedikit atau terlalu banyak. Sikap orang ketika sedang bermain game, bisa saja berbeda ketika orang itu sedang tidak bermain game, karena ketika orang tersebut sedang bermain game maka dia akan merasa sedang berada di "dunia" yang game tersebut ciptakan.

Schell [1] menyebutkan bahwa kebanyakan orang biasanya suka memecahkan masalah atau menghadapi tantangan. Game pasti menyediakan masalah dan tantangan untuk dihadapi oleh pengguna, jika game tidak menyediakan tantangan maka game tersebut akan kurang menyenangkan untuk dimainkan. Game juga menyediakan goals (tujuan) untuk pengguna, sehingga pengguna mempunyai tujuan dalam memainkan game tersebut, jika game tidak mempunyai goals mungkin pengguna akan menemukan bahwa game tersebut membosankan.

\subsection{Genre Game}

Gameplay dalam game dibedakan menurut genre-nya yang sekarang ini sudah bermacam-macam[2]. Genre juga mempunyai tugas untuk membatasi para perancang game untuk dapat berkreasi dalam ide yang lebih 
spesifik. Genre juga mempunyai tugas untuk membatasi para perancang game untuk dapat berkreasi dalam ide yang lebih spesifik. Di dalam satu game juga dapat mengandung lebih dari satu genre yang disebut dengan hybrid genre. Macam-macam genre game yaitu Action Games, Strategy games, Role-Playing Games, Sports Games, Racing/Driving Games, Simulation/Building Games, Flight and Other Simulations., Adventure Game, Edutaintment, Children's Games, Casual Games

\subsection{Game Engine}

Game engine[3] merujuk pada kumpulan modul kode simulasi yang tidak secara langsung menentukan perilaku permainan (game logic) atau lingkungan permainan (level data). Game engine mencakup modul untuk menangani input, output (3D Rendering, gambar 2D, suara) dan generic physics atau dinamika untuk dunia game.

Ada banyak game engine yang dirancang untuk bekerja pada konsol video game dan sistem operasi desktop seperti Microsoft Windows, Linux, dan Mac OS X. Fungsi utama yang disediakan oleh game engine biasanya adalah render ( renderer) untuk grafis 2D atau 3D, suara, script, animasi, kecerdasan buatan, jaringan, streaming, manajemen memori, threading, dukungan lokalisasi, dan adegan grafik. Game engine biasanya menyediakan platform abstraksi, yang memungkinkan permainan yang sama untuk dijalankan pada berbagai platform termasuk konsol game dan komputer pribadi dengan perbedaan yang tidak besar. Game engine yang membantu dalam membuat keputusan untuk menentukan frame sampai menentukan artwork yang ada di dalam scene

\subsection{Unity $3 D$}

Unity[4] salah satu game engine yang mudah digunakan, hanya membuat objek dan diberikan fungsi untuk menjalankan objek tersebut. Dalam setiap objek mempunyai variabel, variabel inilah yang harus dimengerti supaya dapat membuat game yang berkualitas. Berikut ini adalah bagian-bagian dalam Unity: .Asset yang adalah tempat penyimpanan dalam Unity yang menyimpan suara, gambar, video, dan tekstur. Scenes adalah area yang berisikan konten-konten dalam game, seperti membuat sebuah level, membuat menu, tampilan tunggu, dan sebagainya. Game Objects adalah barang yang ada di dalam assets yang dipindah ke dalam scenes, yang dapat digerakkan, diatur ukurannya dan diatur rotasinya. Components adalah reaksi baru, bagi objek seperti collision, memunculkan partikel, dan sebagainya. Script, yang dapat digunakan dalam U nity ada tiga, yaitu Javascript, C\# dan BOO. Prefabs adalah tempat untuk menyimpan satu jenis game objects, sehingga mudah untuk diperbanyak.

\subsection{Metode Rapid Game Prototyping}

Pada penelitian ini, penulis menggunakan metode rapid game prototyping yang adalah metode hasil modifikasi dari metode pengembangan perangkat lunak cepat pemrograman ekstrem.

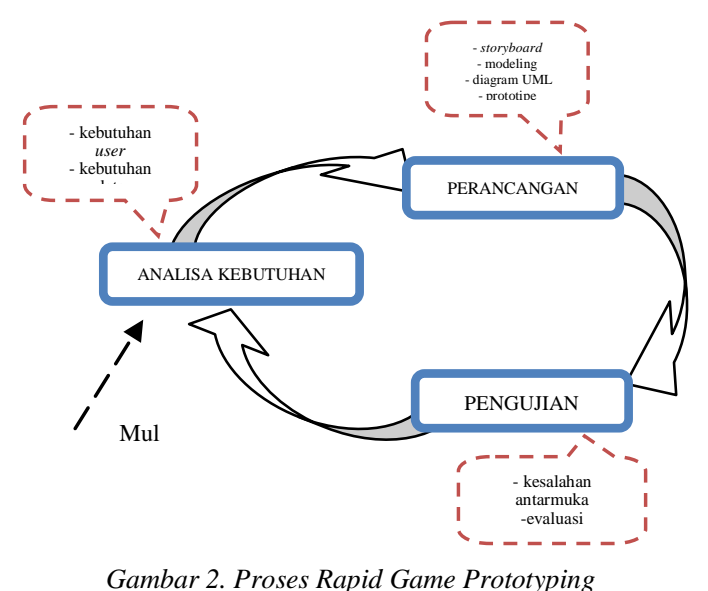

Terdapat 3 proses dalam metode rapid game prototyping ini:

a) Analisa Kebutuhan

Analisa kebutuhan dilakukan untuk mengetahui kebutuhan user, kebutuhan data dan user stories.

b) Perancangan

Pada proses ini yang dilakukan adalah membuat storyboard, merancang model 3D alat musik bambu sampai ke tahap materliazing, diagram uml yaitu use case dan activity diagram kemudian prototyping

c) Pengujian

Prototipe game yang telah selesai dibuat selanjutnya diuji menggunakan teknik pengujian perangkat lunak kotam hitam (Black Box) kemudian dilakukan evaluasi 


\section{PEMBAHASAN}

\subsection{Tahap Analisa Kebutuhan}

Tahap ini bertujuan mengidentifikasi kebutuhan user, kebutuhan data dan user stories.

a) Kebutuhan user, digunakan sebagai acuan dalam membuat user interface dan fitu-fitur dalam game yang dikumpulkan dengan membagikan kuisioner yang berisikan beberapa pertanyaan kepada 20 orang responden. (diagram hasil pengolahan kuisioner dapat dilihat pada gambar 3)

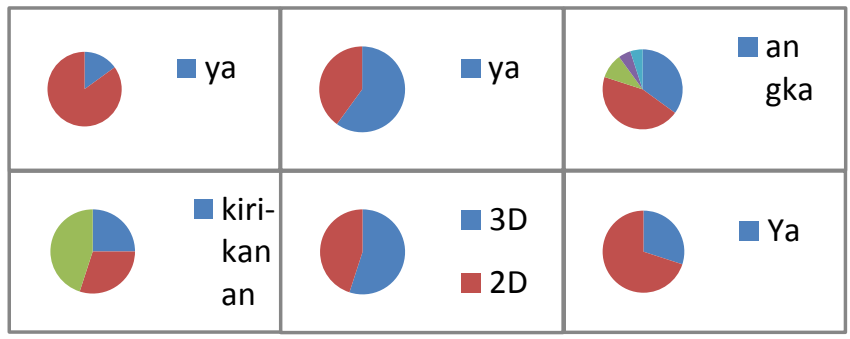

Gambar 3. Hasil Kuisioner

b) Data pada game ini adalah gambar alat musik bambu (lihat gambar 4) yang akan dijadikan acuan dalam membuat model 3D dan bunyi yang dihasilkannya untuk dijadikan sebagai suara dalam game.

c) User stories adalah salah satu artifak dari tahap analisa kebutuhan. Tujuan dibuatnya User stories adalah untuk mengetahui kebutuhan yang di dalamnya terdapat user, role, dan apa yang bisa dilakukan oleh role tersebut. User Stories game musik bambu dapat dilihat pada tabel 1.

\begin{tabular}{|c|c|c|c|c|}
\hline ID & \multicolumn{3}{|c|}{ STORY TITLE } & STATUS \\
\hline 1 & \multicolumn{3}{|c|}{$\begin{array}{l}\text { Sebagai pengguna saya ingin menikmati tampilan yang } \\
\text { menarik dalam game musik bambu }\end{array}$} & Selesai \\
\hline 2 & \multicolumn{3}{|c|}{$\begin{array}{l}\text { Sebagai pengguna saya dapat melihat alat musik bambu } \\
\text { dalam game }\end{array}$} & Selesai \\
\hline 3 & \multicolumn{3}{|c|}{$\begin{array}{l}\text { Sebagai pengguna saya dapat mendapat pengetahuan } \\
\text { dengan memainkan game musik bambu }\end{array}$} & Selesai \\
\hline 4 & \multicolumn{3}{|c|}{$\begin{array}{l}\text { Sebagai pengguna saya dapat berinteraksi dan } \\
\text { mengendalikan karakter game }\end{array}$} & Selesai \\
\hline & \multirow{3}{*}{\multicolumn{2}{|c|}{ Actors: }} & \multicolumn{2}{|c|}{$\begin{array}{l}\text { Pengembang: Orang yang bertanggung jawab dalam pembuatan } \\
\text { game ini }\end{array}$} \\
\hline & & & \multicolumn{2}{|c|}{ Desainer: Orang yang membuat desain objek 3D } \\
\hline & & & \multicolumn{2}{|c|}{ Pengguna: Orang yang akan memainkan game } \\
\hline & \multicolumn{4}{|c|}{ Sebagai Pengembang } \\
\hline & User Story ID & & I Want.... \\
\hline & 1 & \multicolumn{2}{|c|}{ Game ini memiliki tampilan yang menarik } & $\begin{array}{l}\text { Menambahkan Desainer ke } \\
\text { dalam proyek }\end{array}$ \\
\hline & 2 & \multicolumn{2}{|c|}{ Menampilkan alat musik bambu dalam game } & $\begin{array}{l}\text { Memasukan objek 3D alat } \\
\text { musik bambu ke dalam game }\end{array}$ \\
\hline & 3 & \multicolumn{2}{|c|}{ Memberikan pengetahuan kepada pengguna } & $\begin{array}{l}\text { Menambahkan catatan teori } \\
\text { musik bambu di dalam game }\end{array}$ \\
\hline & 4 & \multicolumn{2}{|c|}{ Pengguna dapat mengendalikan karakter } & $\begin{array}{l}\text { Membuat karakter dalam } \\
\text { bentuk first-person }\end{array}$ \\
\hline & \multicolumn{4}{|c|}{ Sebagai Pengguna } \\
\hline & User Story ID & \multicolumn{2}{|c|}{ I Want To.... } & So that.... \\
\hline & 1 & \multicolumn{2}{|c|}{ Menikmati tampilan menarik } & Tertarik memainkan game \\
\hline & 2 & \multicolumn{2}{|c|}{ Melihat alat musik bambu } & Mengetahui alat musik bambu \\
\hline & 3 & \multirow{2}{*}{\multicolumn{2}{|c|}{$\begin{array}{l}\text { Mendapat pengetahuan } \\
\text { Mengendalikan karakter }\end{array}$}} & Mengenal alat musik bambu \\
\hline & 4 & & & \begin{tabular}{|l|} 
Berinteraksi dengan game \\
\end{tabular} \\
\hline
\end{tabular}

Tabel 1. User Stories Game Musik Bambu

\subsection{Tahap Perancangan}

a) Storyboard

Pada tahap ini dibuatlah storyboard dari masing-masing scene permainan. Salah satu storyboard dapat dilihat pada tabel 2 


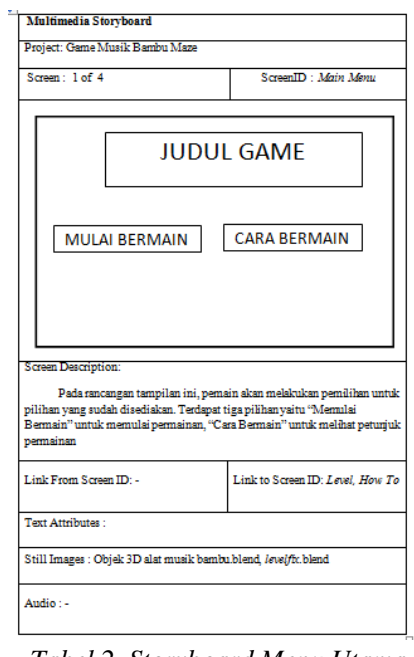

b) $3 D$ Modeling

Gambar alat musik bambu yang telah dikumpulkan kemudian dibuat model 3D sampai pada tahap materializing

c) UML Diagram

Use case diagram digunakan untuk merepresentasikan interaksi antara pemain dengan game. Activity Diagram menggambarkan berbagai alur kegiatan secara umum yang ada di dalam game, mulai dari awal dimulainya game, decision yang akan terjadi dan sampai berakhirnya.

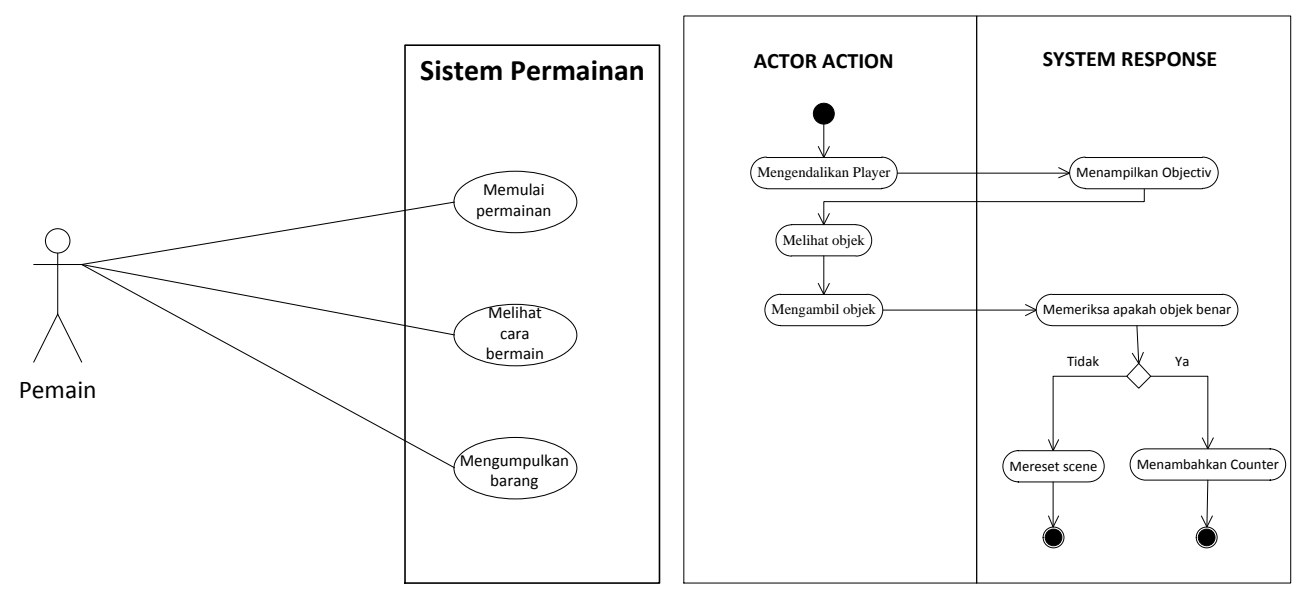

Gambar 5. Use Case Diagram dan Activity Diagram

d) Prototyping

Pada tahap ini yang dilakukan adalah memasukan model 3D ke dalam Unity kemudian membuat perintah-perintah dalam game.

\subsection{Tahap Pengujian}

a) Pengujian Blackbox

Pengujian blackbox dilakukan untuk mengetahui kesalahan-kesalahan apa yang terdapat pada antar muka game. Pengujian dilakukan terhadap beberapa fitur yang sudah ditetapkan. Hasil pengujian blackbox dapat dilihat pada Tabel 3. 


\begin{tabular}{|c|c|c|c|c|}
\hline Foeanes & Evpocsed Rosut & $\begin{array}{c}\text { Yot } \\
\text { Expoctmaion }\end{array}$ & Proof & Comonent \\
\hline $\operatorname{sing} y$ & 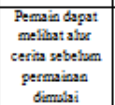 & No & - & $\begin{array}{c}\text { Dapat } \\
\text { Obembunglan } \\
\text { selagionys }\end{array}$ \\
\hline Play Gant & \begin{tabular}{c|} 
Pemain dapat \\
memmisi \\
permainas
\end{tabular} & Yes & Gambar 4.2 & - \\
\hline $\operatorname{siggt}$ & $\begin{array}{c}\text { Pemain dapat } \\
\text { memainkan } \\
\text { permainas } \\
\text { dengas } \\
\text { inglatan level }\end{array}$ & Yes & Gambar 4.4 & 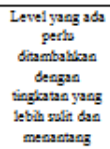 \\
\hline Resull Serten & \begin{tabular}{c|} 
Pemain dapas \\
mellast havd \\
abhir dari \\
permanas
\end{tabular} & Yes & Gambar 4.7 & - \\
\hline Atkisvimatet & 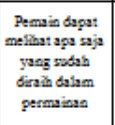 & No & - & 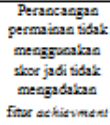 \\
\hline rasm & \begin{tabular}{c|} 
Pemain dapat \\
mengambil htem
\end{tabular} & Yes & $\begin{array}{c}\text { Gambar } 4.5, \\
4.6\end{array}$ & . \\
\hline option & 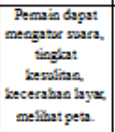 & No & - & 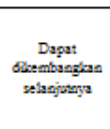 \\
\hline Pasest Gand & $\begin{array}{c}\text { Pemain daput } \\
\text { mengbentan } \\
\text { permainse sast } \\
\text { permainsa } \\
\text { beflangsuag }\end{array}$ & No & - & 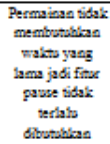 \\
\hline
\end{tabular}

Tabel 3. Hasil Pengujian Blackbox

\section{b) Evaluasi Pengguna}

Evaluasi pengguna dilakukan dengan membagikan kuisioner yang di dalamnya terdapat 6 buah pertanyaan, evaluasi ini dilakukan dengan tujuan untuk mengetahui bagaimana respon pemain terhadap game musik bambu. Hasil pengolahan kuisioner dapat dilihat pada gambar 7.

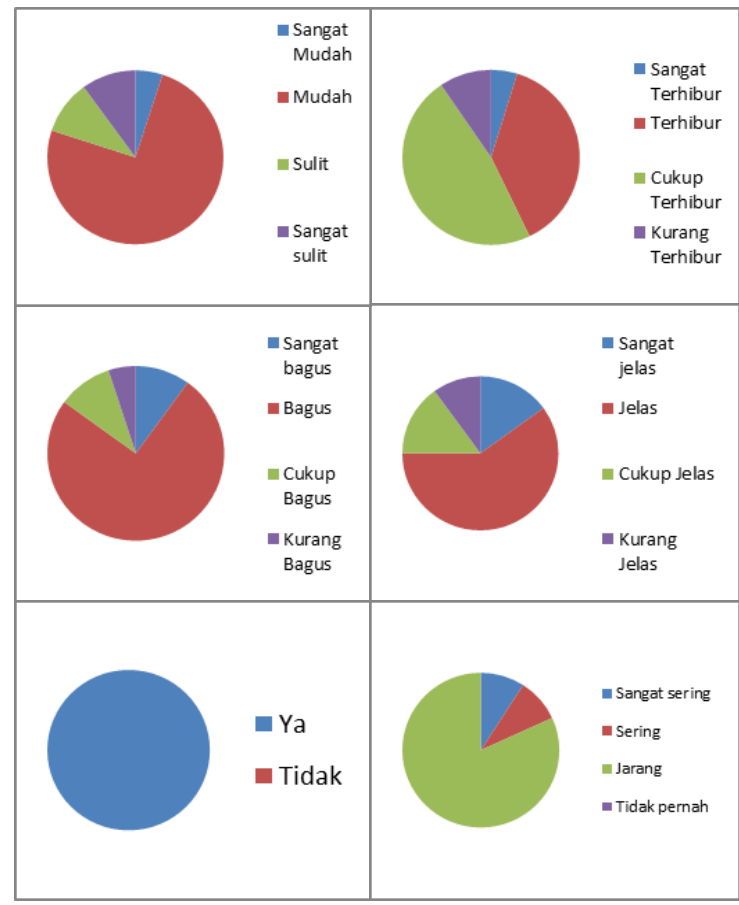

Tabel 2. Hasil Evaluasi Pengguna 


\section{SIMPULAN DAN SARAN}

Kesimpulan yang dapat diberikan dari pembuatan prototipe game musik bambu ini adalah menghasilkan prototipe game musik bambu yang bertemakan collectible dengan mode permainan first-person dengan mengimport objek 3D dari Blender yang kemudian dijadikan Game Object dalam Unity. Dari hasil evaluasi pengguna, prototipe game ini memberi pengetahuan kepada pemain mengenai alat musik bambu dan membuat pemain terhibur, juga game ini memiliki tampilan yang cukup bagus dan objek alat musik bambu di dalamnya dapat dilihat dengan jelas.

Saran untuk pengembangan:

Untuk menyempurnakan prototipe game musik bambu yang telah dibuat agar dapat lebih baik lagi dan dapat dipublikasikan secara global maka perlu dilakukan pengembangan lebih lanjut, yaitu mengembangkan game agar memiliki lebih banyak level, agar permainan tidak terkesan terlalu mudah juga perlu ditambahkannya objek alat musik bambu dalam game agar pemain dapat mengetahui lebih banyak jenis alat musik bambu.

\section{DAFTAR RUJUKAN}

[1] Schell, Jesse.2008. The Art of Game Design - A Book of Lenses. Morgan Kauffman Publisher, Burlington Sutanto Leo. (2008), Kiat Sukses Mengelola \& Mengajar Sekolah Minggu, Yogyakarta: ANDI Offset.

[2] Fullerton, T. 2008. Game Design Workshop, Second Edition: A Playcentric Approach to Creating Innovative Games (Gama Network Series) Morgan Kaufmann

[3] Lewis, Michael \& Jacobson, Jeffrey. 2002. Game Engines in Scientific Research. Communications Of The Acm, No. 1 Vol. 45 , h. $27-31$.

[4] Sari P. Z., Nugroho, H., Jatmiko, A., Agung, A.2013. Aplikasi Game Action RPG 'RUGEN THE WIGOON MASTERPIECE' Pada Platform Android Dengan Menggunakan Unity. Skripsi Program S1 Teknik Informatika Universitas Bina Nusantara. Jakarta Barat

[5] Pressman, Roger and Lowe, David. (2009), Web Engineering A Practitioner's Approach., McGrawHill. 